\title{
Comparative Migration and Development of Astroglial and Oligodendroglial Cell Populations from a Brain Xenograft
}

\author{
C. Jacque, ${ }^{1}$ J. Quinonero, ${ }^{1}$ P. V. Collins, ${ }^{2}$ H. Villarroya, ${ }^{1}$ and I. Suard' \\ IINSERM U-134, Hôpital de la Salpêtrière, 75651 Paris Cédex 13, France and 2Ludwig Institute for Cancer Research, \\ S-10401, Stockholm, Sweden
}

In previous studies of brain transplantation, the fate of the implanted glial cells has been investigated separately; that is, the interest has been focused either on the astroglia or on the oligodendroglia. However, the two populations of implanted glial cells may interact with each other, for example by secreting species-specific factors or by inducing reactions by the host. We have used two different models of brain transplantation: one that allows the identification of the implanted astrocytes, and another that allows the identification of the implanted oligodendroglia. The present model is a combination of both; it consists of the grafting of embryonic rabbit brain fragments into the brains of neonatal Shiverer mice. The myelin made by the implanted oligodendrocytes is identified by anti-myelin basic protein immunohistochemistry. The implanted astrocytes are identified by a monoclonal antibody that combines with rabbit but not with mouse glial fibrillary acidic protein.

This study shows that although they use the same major routes of migration, both populations of glial cells tend to move differently. They demonstrate areas of common settlement but also areas where only one population of implanted glia is present. From the site of implantation in the dorsal striatum, the major routes of migration are the corpus callosum, the white matter fascicles in the striatum, and the internal capsule. After a delay of 6 weeks, no significant prevalence of one population of implanted glial cells over the other was observed.

The capacity of implanted glial cells to migrate in host brains is of crucial importance in brain transplantation. Cells that have been introduced at specific sites will be able to settle in different areas of the brain. We must learn more about the rules that govern these migrations in order to anticipate the sites where the implanted glial cells will settle. This is of peculiar importance since most protocols in brain transplantation use whole fragments of tissue that contain a mixture of cell populations, notably astroglia and oligodendroglia. However, each research group in the field of transplantation limits its interest to only one

\footnotetext{
Reccived Sept. 6, 1991; revised Jan. 27, 1992; accepted Mar. 17, 1992.

This work received the financial support of the INSERM and funds from the Association pour la Recherche sur la Sclerose en Plaques (ARSEP). We thank Dr. John Booss for review of the manuscript and Dr. Nicole Baumann for constant encouragement. We also thank P. Guilmain for her care in raising the experimental mice.

Correspondence should be addressed to Claude M. Jacque, INSERM U-134, Hôpital de la Salpêtrière, 47 Boulevard de l'Hôpital, 75651 Paris Cédex 13, France. Copyright (c) 1992 Society for Neuroscience $0270-6474 / 92 / 123098-09 \$ 05.00 / 0$
}

population of cells, usually ignoring the fate of the others. However, the outcome of implanted cells of one type is likely to be modified by simultaneous introduction in the grafted brain of other cell types. In brain transplantation into the newborn, both types of macroglial cells have been shown to survive and migrate in host brains. The Shiverer model has been used to demonstrate the capacity of implanted oligodendrocytes to myelinate host axons, sometimes at a long distance from the site of implantation (Gumpel et al., 1983; Baulac et al., 1987). Extensive migration of implanted astrocytes has also been described by several groups after brain transplantation into newborn (Jacque et al., 1986; Suard et al., 1989; Zhou et al., 1990) or adult (Lindsay and Raisman, 1984; Goldberg and Bernstein, 1988) hosts. Our group has developed a rabbit-into-mouse brain transplantation model that takes advantage of the property of a monoclonal antibody, called Tp-GFAP 1, to combine with rabbit (Jacque et al., 1986) but not with mouse (Collins and Moser, 1983) glial fibrillary acidic protein (GFAP) under appropriate fixation conditions (Bell et al., 1987). With this model, we have observed extensive migration of transplanted astrocytes throughout host brains (Jacque et al., 1988; Suard et al., 1989) and have shown that the extension and direction of these migrations are independent from the region of origin of the transplant in the donor's brain (Jacque et al., 1991).

Until now, there have been no reports comparing the fates of both populations of macroglial cells after implantation. The survival and migration of oligodendrocytes and astrocytes may not be the same if the cells migrate as committed cells. They may take different pathways when leaving the transplant and settle at different sites. Conversely, if the cells migrate as bipotential precursors and differentiate once in place, they should occupy superimposable areas in the host brain. Finally, if the precursors are not common, oligodendrocytes and astrocytes may be found in different areas of the recipient's brain. In this article, we compare the topographic distributions of both astroglial and oligodendroglial cell populations derived from a transplant. After transplantation of fragments from the corpus callosum of rabbit embryos into the striatum of newborn mice, the two macroglial cell populations from the donor species were often found to occupy fields in common but could also be seen to segregate in different areas.

\section{Materials and Methods}

Donor tissues. Pregnant New Zealand rabbit females carrying embryonic day 25 (E25) embryos were anesthetized with successive intravenous inoculation of Vetranquil (Clin-Midy, Montpellier, France) and Imalgène (Rhône-Mérieux, Lyon, France), $1 \mathrm{ml}$ of each. The embryos were collected and killed, and their brains were removed and placed in cold 



Figure 1. Immunohistochemical and bisbenzimide staining on frozen sections from a brain collected 4 weeks AG. Magnification, $150 \times$. A, Bisbenzimide fluorescence showing the nuclei of all of the implanted cells whatever their type and differentiation stage. The cells most positively stained are grouped by the charcoal bits (arrows). B. Staining with MBP antibodies showing the presence of myelin sheaths made by donor's oligodendrocytes at the implantation site (arrows), but also at distance from it (arrowheads) in areas where the fluorescence due to the bisbenzimide is much paler. $C$, Staining with GFAP polyclonal antibody showing the astroglial activation due to the transplant. $D$ (same tissue section as $C$ ), Double staining with $\mathrm{Tp}-1$ demonstrating the presence of donor astrocytes at the site of implantation (arrows) and on migration (arrowheads).

saline. The corpus callosum was dissected out and cut into pieces 0.3 $\mathrm{mm}$ in size. After mixing with charcoal, the transplants were introduced immediately into the brains of recipient mice with a maximum delay of $1 \mathrm{hr}$ for the last implantation.

In some instances, the transplant was incubated with the fluorescent dye bisbenzimide (Hoechst 33342; Sigma, l'Isle d'Abeau, France) prior to implantation in order to label the cells in the transplant (Gansmüller et al., 1991).

Host animals. Newborn Shiverer mice from the C57/B1 6J strain were cold anesthetized before receiving the transplant in the right half of their striatum. The transplant was pushed gently into the brain through a glass pipette connected with a low-flow pump. The pipette was maintained in place for $20 \mathrm{sec}$ minimum in order to avoid loss of the transplant due to temporary rebound pressure in the grafted brain. The animals were warmed under a lamp, mixed with their own bedding, and given back to their mother.

Tissue collection and processing. After survival times ranging from 12 to $80 \mathrm{~d}$, the grafted mice were perfused through the heart with $2 \%$ paraformaldehyde. The brains were removed and immersed in successive batches of the same fixative containing $0 \%, 10 \%$, and $20 \%$ sucrose. After rinsing in cold PBS, the brains were frozen for cryostat sectioning at $10 \mu \mathrm{m}$. In some instances, the brains or the sections were stored for up to a few days in a sealed box maintained at $-26^{\circ} \mathrm{C}$ prior to use. Sagittal sections were made throughout the brains in order to have a full view of the potential migration patterns.

Immunohistochemistry. Sections were delipidated either in ethanol, $5 \mathrm{~min}$ at room temperature, for the myelin basic protein (MBP) staining or in acetone, $10 \mathrm{~min}$ at $-20^{\circ} \mathrm{C}$, for the GFAP staining. The following antibodies have been used: Tp-GFAP 1 (abbreviated Tp-1) for the selective identification of implanted rabbit astrocytes (Jacque et al., 1986; Bell et al., 1987); Tp-GFAP 3 (Zheng et al., 1986), a mouse IgG1 immunoglobulin that combines with the GFAP of any species studied and in the present study serves as a positive control for the Tp-1 immunostaining; rabbit polyclonal anti-GFAP (Dako, Glostrup, Denmark), which identifies both mouse and rabbit GFAP; rabbit anti-MBP raised in our laboratory, the specificity of which has been described elsewhere (Lachapelle et al., 1990), for the selective identification of the myelin made by the implanted rabbit oligodendrocytes in MBP-negative Shiverer host brain (Dupouey et al., 1979).

The secondary antibodies were swine anti-rabbit immunoglobulins coupled with tetramethylrhodamine or with fluorescein isothiocyanate (Dako, Glostrup, Denmark) and goat anti-mouse immunoglobulins labeled with fluorescein isothiocyanate (Southern Biotechnologies, Birmingham, AL).

The following double-staining experiments have been performed: $\mathrm{Tp}-1 /$ pGFAP and Tp-1/MBP using appropriate combinations of secondary antibodies. Omission of the primary antibody on sections served to control for the specificity of the secondary antibodies.

Immunostained sections were examined under a Leitz Laborlux fluorescence microscope equipped with filters appropriate for rhodamine and fluorescein emission wavelengths.

\section{Results}

Donor glial cells were found in 44 of 69 grafted mice (Table 1). Most frequently (64\% of positive cases), both astroglial and 

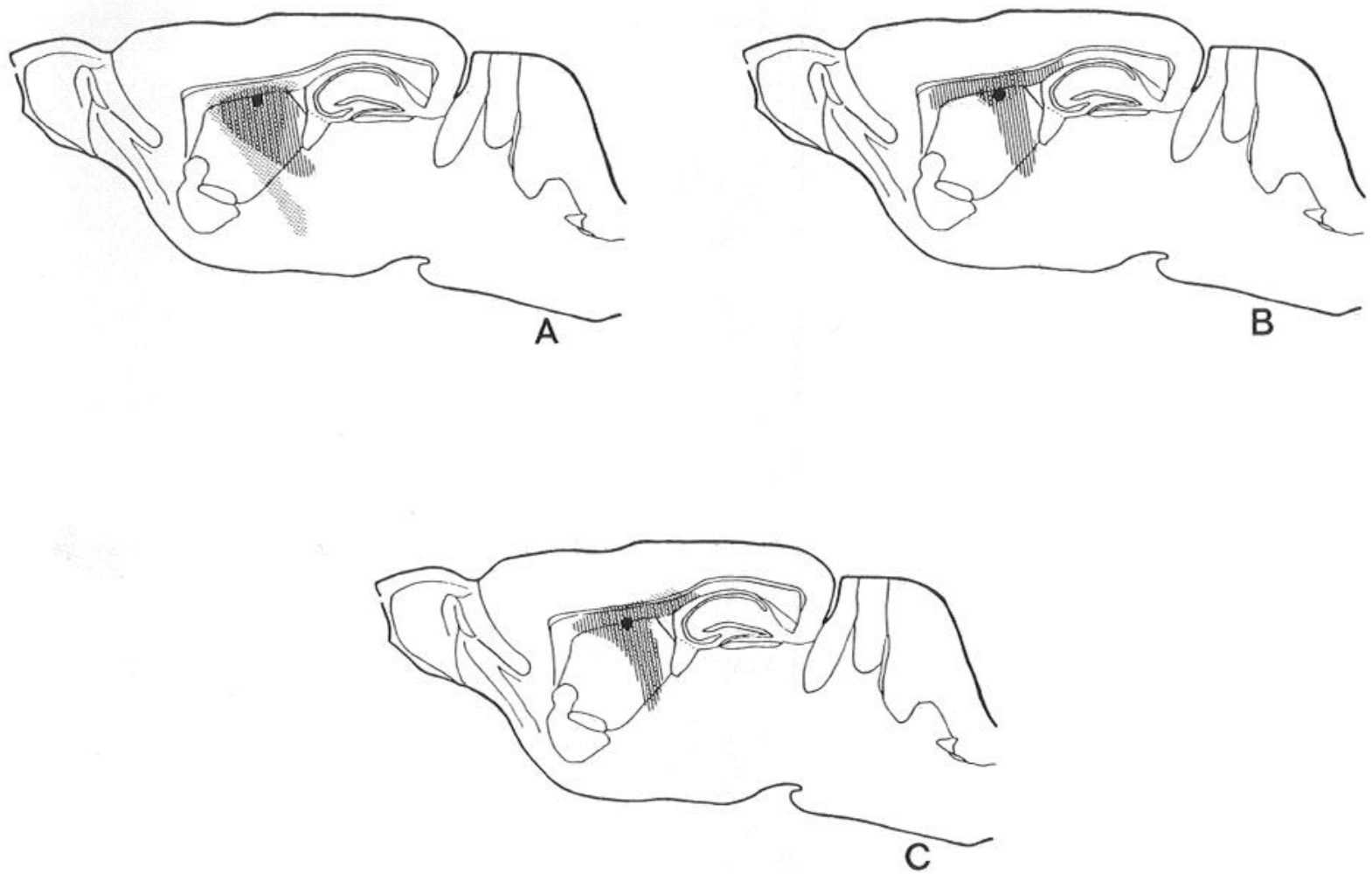

Figure 2. Schematic representation of parasagittal sections from three separate grafted brains $(A-C)$ collected 4-5 weeks AG. Areas populated with transplant-derived oligodendroglia are hatched. Areas populated with transplant-derived astrocytes are dotted. The black spot in the dorsal striatum represents the site of implantation.

oligodendroglial cell populations were present simultaneously. In some instances, only one population of transplanted macroglial cells was found, astrocytes in 7\% and oligodendrocytes in $30 \%$ of the cases with foreign glial cells. We have followed

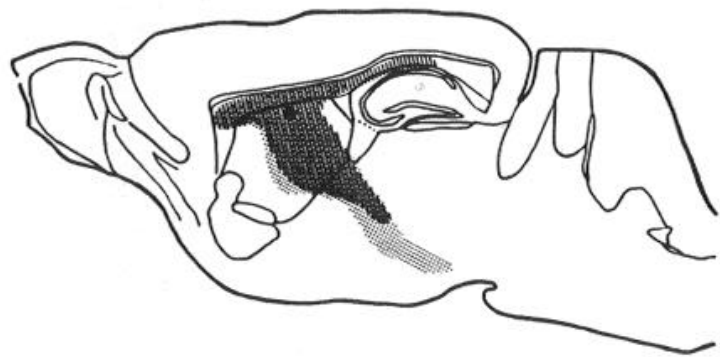

A

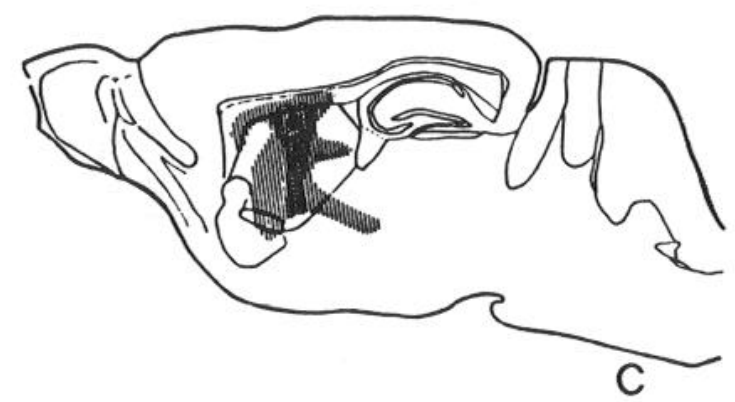

the development of glial cell populations from the graft from $12 \mathrm{~d}$ to 10 weeks after grafting (AG). Since the purpose of this report is the comparison of the migration patterns of astroglial and oligodendroglial cells, we will focus on observations made

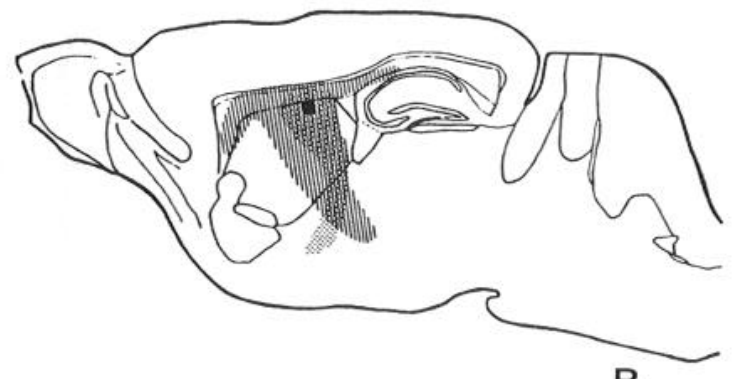

B

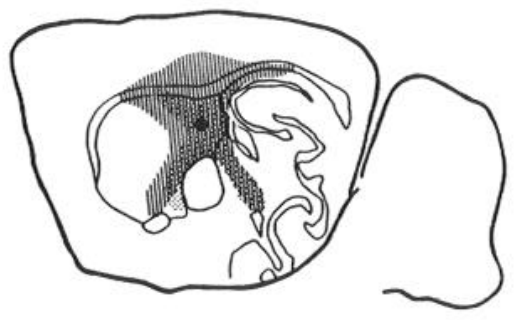

D

Figure 3. Schematic representation of parasagittal sections from four separate grafted brains $(A-D)$ collected 6 weeks AG. For details, see Figure 2 . 

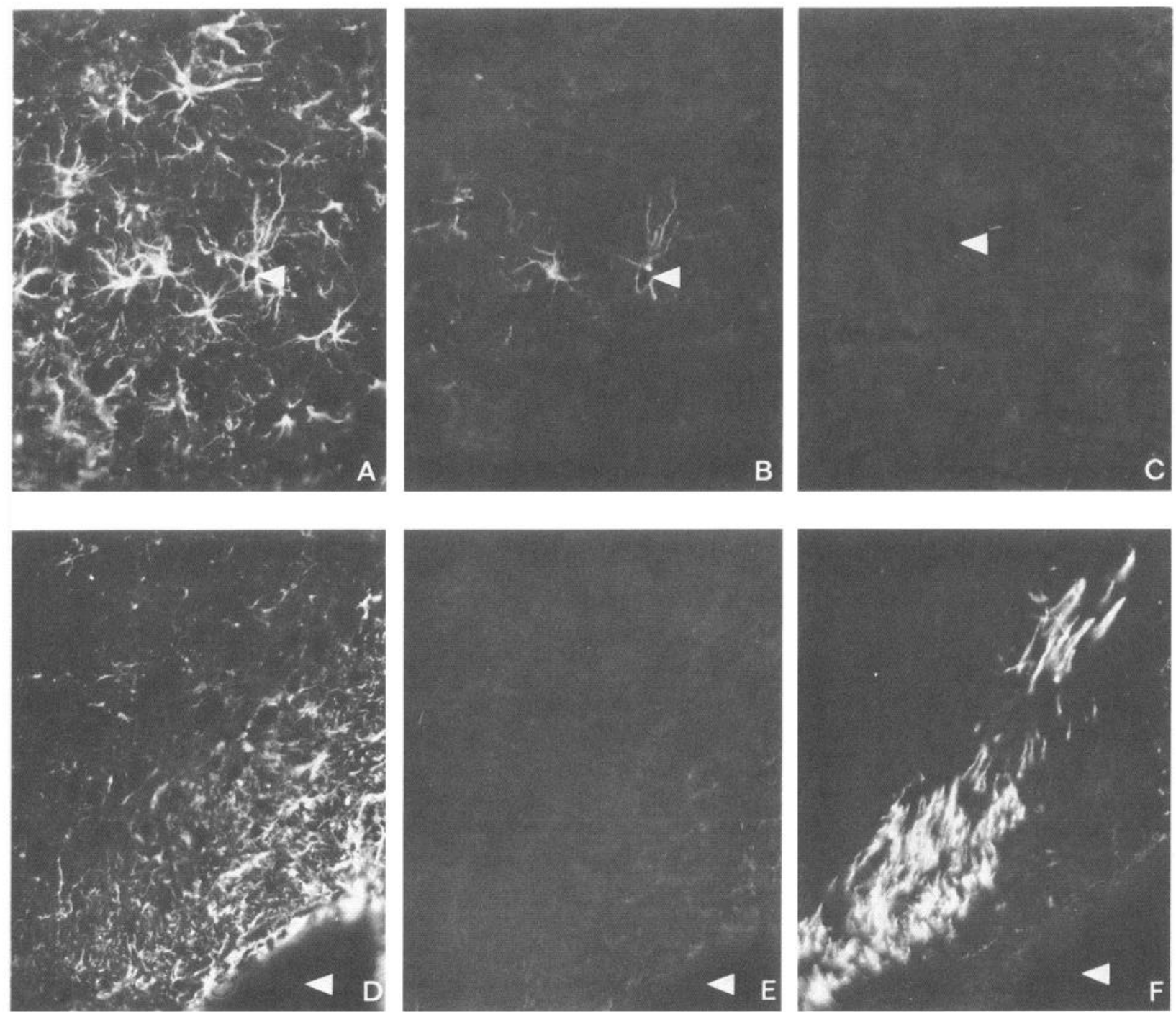

Figure 4. Immunohistochemical staining on frozen sections from grafted brains collected at various delays after implantation. $A$ and $D$ are stained with GFAP polyclonal antibody, $B$ and $E$ are stained with Tp-1 for the demonstration of donor astrocytes, and $C$ and $F$ are stained with MBP polyclonal antibody for the demonstration of myelin made by donor oligodendrocytes. In each series of three photographs $(A-C, D-F)$, GFAP polyclonal antibody and Tp-1 were applied on the same section (double staining), whereas MBP polyclonal antibody was applied on an adjacent section. White triangles have been placed on the photographs to identify corresponding structures on adjacent sections. Magnification, $330 \times$. A$C$, Three weeks AG, a few astrocytes from the donor are visible $(B)$ in this region of the hippocampus, whereas no donor myelin can be detected (C). $D-F$, Six weeks $A G$, in this brain, donor myelin can be seen $(F)$ close to the right lateral ventricle (triangle), whereas donor astrocytes are absent $(E)$.

on grafted brains collected after delays of 3-6 weeks. The advantage of this time period is that such delays allow enough time for the donor glial cells to migrate extensively (Suard et al., 1989) but are not sufficient for significant disappearance of these cells (Booss et al., 1991; Jacque et al., 1991).

\section{Mapping of migrations}

Each brain was cut sagittally from the right parietal edge to the median sagittal plane in 6-8 groups of 8 adjacent sections; thus, 48 to 64 sections were examined for each grafted brain. In each group, we applied the following antibodies: Tp-1, pGFAP, or MBP; a combination of two of these (double staining); or none to control specificity. During brain sectioning, the presence of donor's cells was checked at the microscope under UV examination thanks to the fluorescence due to bisbenzimide (Fig. 1).
Table 1. Summary of the data giving the total number of animals investigated in each series and the number of these mice containing either one or both populations of macroglial cells from the donor

\begin{tabular}{lllll} 
& $\begin{array}{l}\text { Animals } \\
\text { investi- } \\
\text { gated }\end{array}$ & $\begin{array}{l}\text { Tp-1 } \\
\text { positive, } \\
\text { MBP- } \\
\text { negative } \\
\text { cases }\end{array}$ & $\begin{array}{l}\text { MBP- } \\
\text { positive, } \\
\text { Tp-1- } \\
\text { negative } \\
\text { cases }\end{array}$ & $\begin{array}{l}\text { Cases } \\
\text { positive } \\
\text { for both } \\
\text { MBP and } \\
\text { Tp-1 }\end{array}$ \\
\hline Series 1 & 32 & 3 & 0 & 10 \\
Series 2 & 14 & 0 & 7 & 6 \\
Series 3 & 16 & 0 & 0 & 11 \\
Series 4 & 7 & 0 & 6 & 1 \\
Total & 69 & 3 & 13 & 28 \\
\hline
\end{tabular}



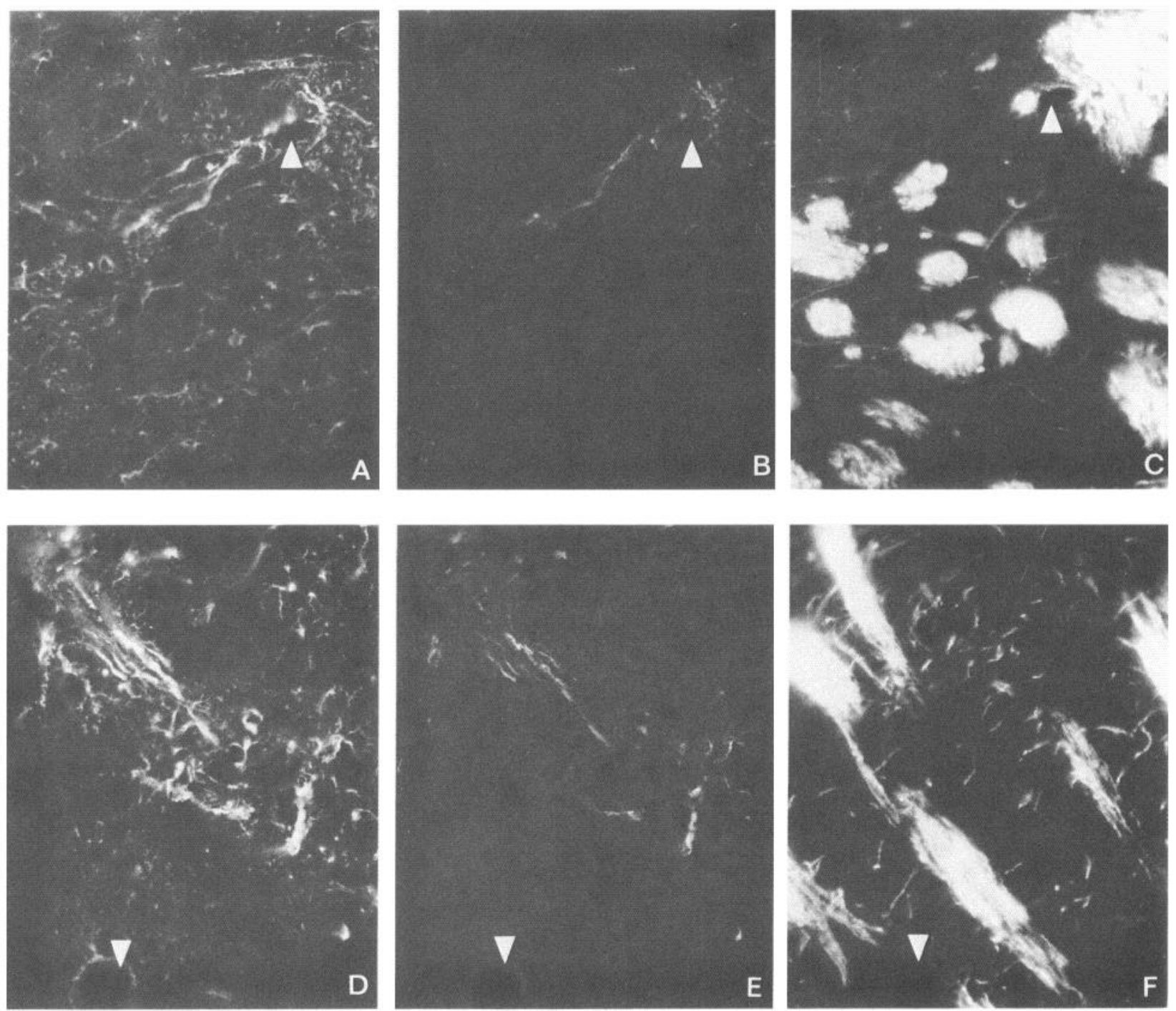

Figure 5. Immunohistochemical staining of sections, as in Figure 4. $A-C$, Six weeks AG, a few donor astrocytes are visible $(B)$ in this region of the striatum, whereas numerous neuron fascicles have been myelinated by donor oligodendrocytes $(C)$. $D-F$, Six weeks AG. A few donor astrocytes are visible in the striatum $(E)$ whereas donor myelin is abundant in the same region $(F)$.

For the illustrations, we made drawings from adjacent sections from seven representative brains. Although implanted glial cells were found on several parasagittal sections because of lateral migration, we present only one drawing from a selected plane for each brain.

When present, implanted glial cells were always found in the vicinity of the charcoal marks. In addition, some could be found at variable distances. In all seven cases including a prelabeling step with bisbenzimide, the cells most positively stained with the dye were located at the center of the implantation site. A decreasing gradient of fluorescence was observed with increasing distances of migration (Fig. 1). The major routes of migration for both cell types from the dorsal striatum were the corpus callosum, the internal capsule, and neuronal fascicles in the striatum (Figs. 2, 3). Glial cells migrated in both directions along the corpus callosum: caudally and rostrally from the site of implantation. The longest distances of migration were variable from one case to another. The total surface on a tissue section occupied by the implanted glial cells was also variable. The relative surfaces occupied by astroglia and oligodendroglia from the donor also varied from one case to another (compare Figs. $2 B, 3 A$ ). Either of these two populations could be seen to prevail, sometimes considerably as in Figure $2 B$. Occasionally, one of the populations of donor glial cells was absent whereas the other was present (Table 1). The missing population could be either one, although it was more often the astroglia. In some instances, implanted oligodendroglia and astroglia were found in completely different areas. For example, in the case presented in Figure $2 A$ oligodendroglial cells have reached the internal capsule whereas an important group of astroglial cells switched to a more ventral direction and reached the anteroventral thalamus. In many instances, although on the same route, they did not stop in the same areas. One population had moved farther than the other (all cases, but notably Figs. $2 C, 3 A, B$ ).

\section{Comparative localization of both populations of macroglial} cells

For a more detailed comparison of the respective areas occupied by both populations of implanted glial cells adjacent sections were examined: one was stained for the MBP, the other was 

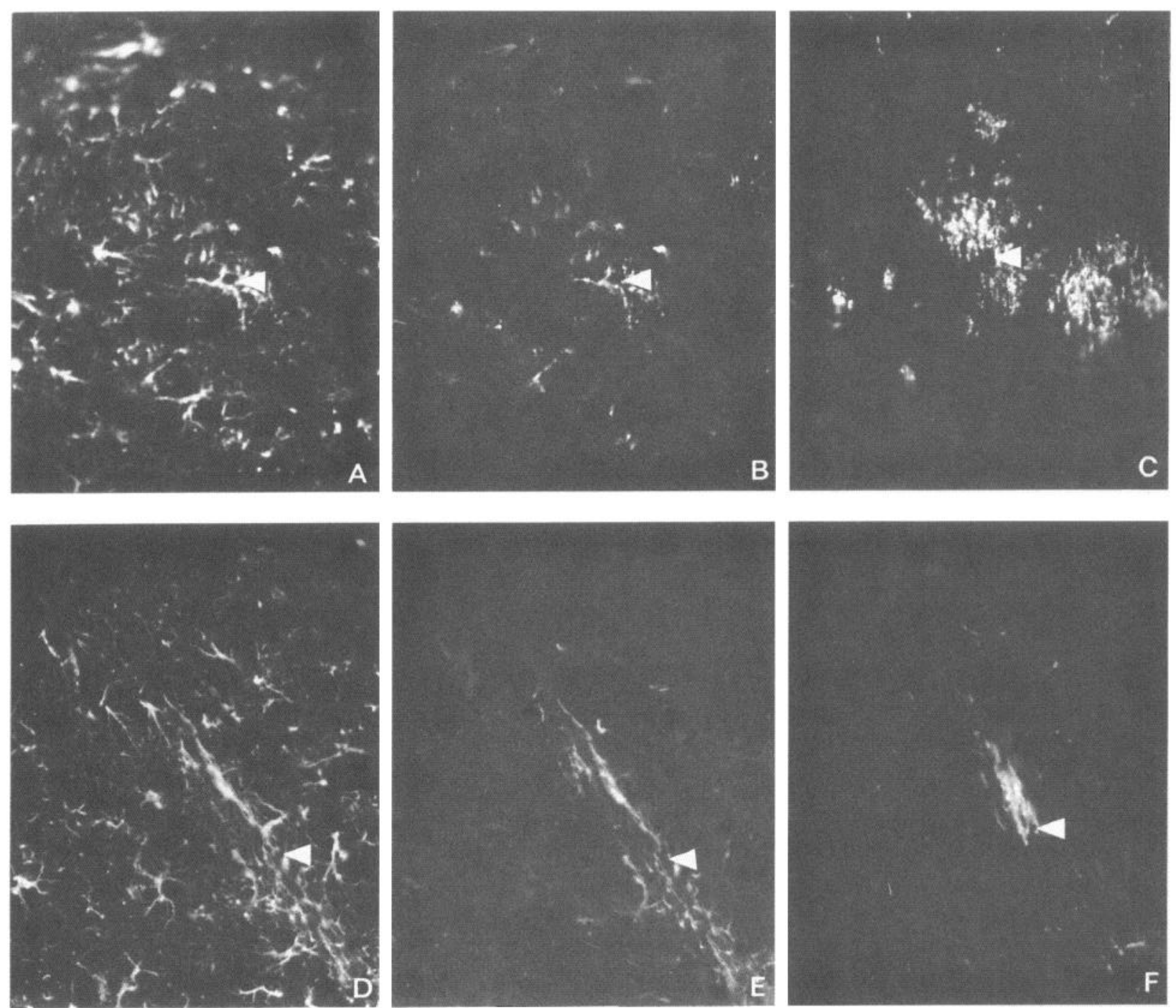

Figure 6. Immunohistochemical staining of sections, as in Figure 4. $A-C$, Six weeks AG, tiny populations of oligodendroglial and astroglial cells ( $B$ and $C$, respectively) from the transplant have developed in the striatum in this grafted brain. $D-F$, Six weeks AG. A few macroglial cells of both types from the donor are present in the striatum.

double-stained by both Tp-1 and pGFAP antibodies. In grafted brains where both populations of transplanted glial cells had developed, some regions were found to contain only one macroglial cell type, either the astrocytes (Fig. $4 A-C$ ) or the oligodendrocytes and their myelin product (Fig. $4 D-F$ ). Most often, both populations of implanted glia colocalized, but they occupied areas of unequal sizes (Fig. $5 B, C ; E, F$ ) or were slightly shifted (see Fig. $7 B, C$ ). In some instances, both populations of implanted macroglial cells occupied areas in common (Fig. $6 B, C$; $E, F)$, whereas in other fields superimposition was only partial (Fig. $7 B, C, E, F ; H, I$ ).

\section{Discussion}

Several studies have shown the propensity of glial progenitor cells to migrate after intracerebral implantation of tissue fragments from immature CNS. Whatever the region of origin in the donor's brain and the site of implantation in the host, the implanted glial cells leave the graft and settle at various distances after having moved along white matter tracts and blood vessels, which are the favorite routes of migration (Lindsay and Rais- man, 1984; Baulac et al., 1987; Goldberg and Bernstein, 1988; Reynolds and Wilkin, 1988; Suard et al., 1989; Zhou et al., 1990; Jacque et al., 1991). This has been observed by different laboratories using different models of transplantation for investigations on either implanted oligodendroglia or astroglia. The present report is the first study showing simultaneous observation of both populations of macroglial cells. This model combines the advantages of the Shiverer model to study oligodendroglia transplantation (Gumpel et al., 1983; Lachapelle et al., 1984) and those of the mouse/rabbit model that we have used for several years in astroglia transplantation (Jacque et al., 1986, 1991; Suard et al., 1989). We have now shown that rabbit oligodendrocytes are able to myelinate mouse axons.

The particular question examined in this study is whether astroglial and oligodendroglial cells migrate in common or separately through the host brain tissue after they have left the graft. The transplanted tissue was taken primarily from the corpus callosum, with parts of the subcortex entrapped with it, from E25 rabbit embryos. At that stage of the development the rabbit forebrain does not contain mature macroglial cells. Pos- 

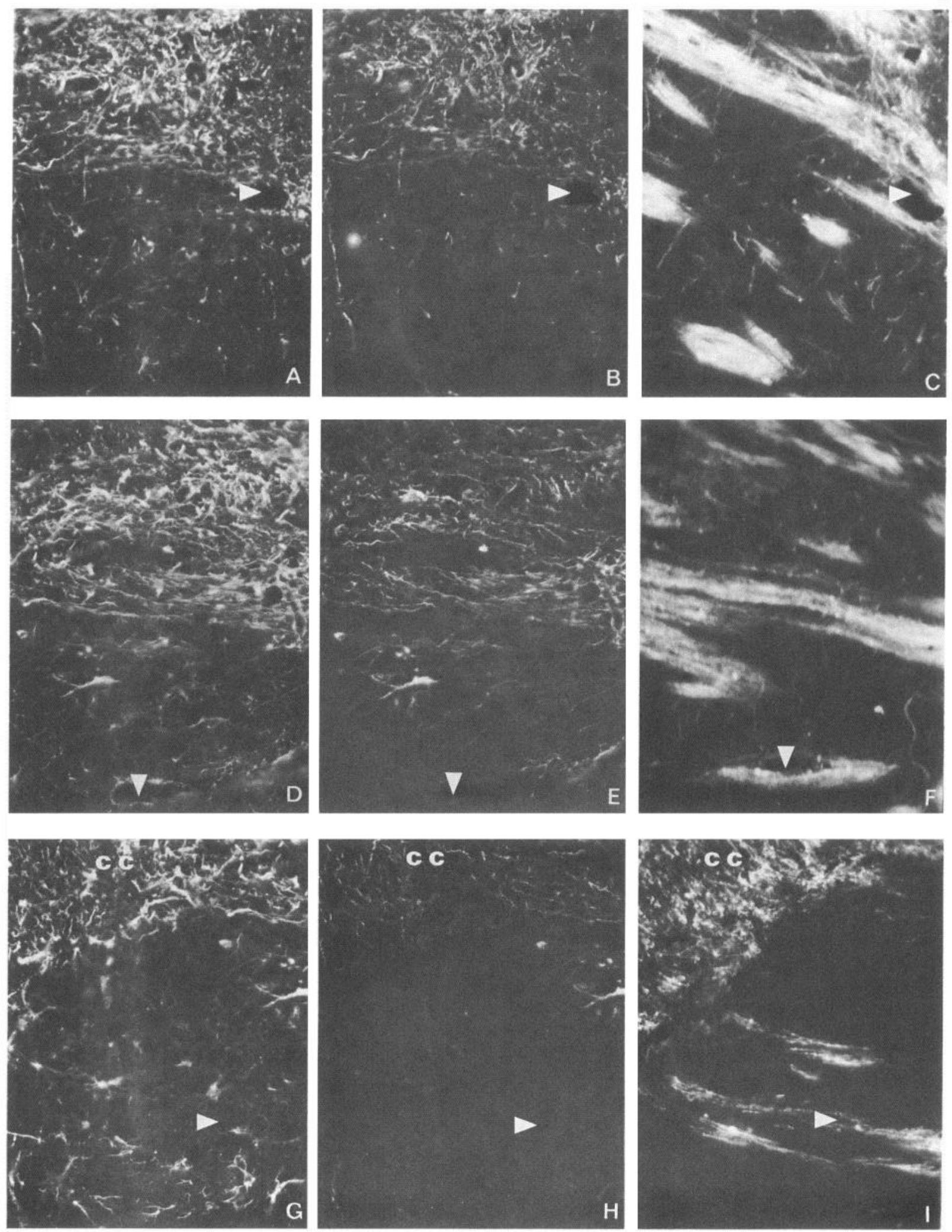

Figure 7. Immunohistochemical staining of sections, as in Figure 4. These three series are taken in the striatum, progressively more frontal from $A$ to $G$, from a brain 6 weeks AG. This figure shows that, even when present in the same region of the host brain, oligodendrocytes and astrocytes from the donor may colocalize largely $(E$ and $F)$, partly $(B$ and $C)$, or minimally $(H$ and $I)$. Photographs $G-I$ are from the region of the striatum, ventral to the genu of the corpus callosum (CC). 
itivity to GFAP antibodies is restricted to radial processes around the lateral ventricles, whereas no positivity can be observed with antibodies to the MBP ( $C$. Jacque and I. Suard, unpublished observations). Thus, at the time of the implantation in the host, the graft contains a population of macroglial cells that are still immature. These glial precursors then undertake migrations and settle at various distances from the site of implantation. For the oligodendrocyte lineage, it is clear that the precursors differentiate into mature cells only after having ceased their migration (Small et al., 1987; Reynolds and Wilkin, 1988). With respect to the astroglial lineage, the situation is not clear. From previous studies, we have evidence that GFAP-positive cells with a bipolar shape are indeed in migration (Jacque et al., 1991). Thus, the capacity for a glial cell to express the differentiation marker GFAP would not necessarily imply that it has reached its final position. However, cells with a starlike or a protoplasmic appearance, or cells participating as subpial or pericapillary glia, which were by far the most frequent forms of the transplanted astroglia in this study, are likely stationary.

It was beyond the scope of this study to assess experimentally the question of bipotentiality of the glial progenitors. However, the observation that areas in the host contained implanted astrocytes but not oligodendrocytes, or the reverse, may mean that once they have settled, the glial cells are already committed. Alternatively, the nonoverlapping localization of both glial cell populations may be due to differential distribution of the signals that define differentiation to a certain lineage. Indeed, unlike astrocytes, which can leave the neuronal fascicles and settle in gray matter areas, myelinating oligodendrocytes always remain in white matter tracts. The data presented here do not distinguish whether precursors to oligodendrocytes and to astrocytes move together to a certain point and then migrate separately, or whether they behave independently from the bcginning of their migrations. This question will be addressed in future research by tracing the implanted cells with fluorescent dyes that are not dependent upon their maturation stage. The preliminary data presented in this report demonstrate the relative stability of one of these potential tracer molecules, bisbenzimide, over a period of time of 4 weeks. However, one must be aware that the efficiency of this method to trace cells may be limited by the progressive loss of fluorescence associated with time, cell division, and probably also cell differentiation.

Although at a close examination both populations of implanted glial cells do not occupy areas exactly in common, the overviews represented in Figures 2 and 3 show that they have moved to the same general regions. This suggests that they often have common migration pathways but that their mobility may be independent. From the site of implantation chosen for this study, the dorsal striatum, the major migration routcs for both populations are the corpus callosum, the myelinated fascicles in the striatum, and the internal capsule. Comigration would be predicted if there is a common precursor cell. However, if the precursor cells are different, the reasons for comigration of the two types of precursors would merit investigation.

Both populations of glial cells appear to be well integrated in the host parenchyma. Since they have ensheathed axons with myelin, the oligodendrocytes are functional. Although their functions are less evident at the immunohistochemical level, the astrocytes present morphological configurations that strongly suggest that they too are well integrated in the host tissue. For example, their positioning as pericapillary glia (Figs. $4 B$, $6 B$ ) implies a functional role. Previous studies had shown that in spite of their apparent initial acceptance by the host, foreign astrocytes are finally rejected after a delay of 2-3 months (Jacque et al., 1988; Booss et al., 1991). With respect to oligodendrocytes, the absence of studies on their long-term maintenance or rejection after xenografting prevents comparison. The lifespan of Shiverer mice does not exceed $3-4$ months, so an investigation of long-term acceptance or rejection of grafted cells is not possible. However, patches of myelin made by implanted oligodendrocytes are still visible at 3 months after allografting (Gansmüller et al., 1986). The transplantation model used in the present study is well suited for comparison of the immunogenicity of oligodendroglial versus astroglial cells. After 1 month, the implanted oligodendrocytes are exposed to T-cells, whose presence is associated with the phase of rejection of the implanted astrocytes (Booss et al., 1991). Whether the oligodendrocytes are identified by lymphocytes as a target or are ignored is of crucial importance for the successful transplantation of brain fragments instead of pure populations of oligodendrocytes in myelin repair programs.

\section{References}

Baulac M, Lachapelle F, Gout O, Berger B, Baumann N, Gumpel M (1987) Transplantation of oligodendrocytes in the newborn mouse brain: extension of myelination by transplanted cells. Anatomical study. Brain Res 420:39-47.

Bell P, Runquist I, Svensson I, Collins P (1987) Formaldehyde sensitivity of a GFAP epitope, removed by extraction of the cytoskeleton with high salt. J Histochem Cytochem 35:1375-1380.

Booss J, Suard I, Collins P, Jacque C (1991) Disappearance of xenogenic astrocytes transplanted into newborn mice is associated with a T-cell response. Brain Res 549:19-24.

Collins VP, Moser R (1983) Monoclonal antibodies to glial fibrillary acidic protein. Acta Pathol Microbiol Scand [A] 91:269-279.

Dupouey P, Jacque C, Bourre JM, Cesselin F, Privat A, Baumann N (1979) Immunochemical studies of myelin basic protein in Shiverer mouse devoid of major dense line of myelin. Neurosci Lett 12:113118

Gansmüller A, Lachapelle F, Baron-Van Evercooren A, Hauw JJ, Baumann N, Gumpel M (1986) Transplantation of newborn CNS fragments into the brain of Shiverer mutant mice: extensive myelination by transplanted oligodendrocytes. II. Electron microscopic study. Dev Neurosci 8:197-207.

Gansmüller A, Clerin E, Krüger F, Gumpel M, Lachapelle F (1991) Tracing transplanted oligodendrocytes during migration and maturation in the Shiverer mouse brain. Glia 4:580-590.

Goldberg W, Bernstein J (1988) Fetal cortical astrocytes migrate from cortical homographs throughout the host brain and over the glia limitans. J Neurosci Res 20:38-45.

Gumpel M, Baumann N, Raoul M, Jacque C (1983) Survival and differentiation of oligodendrocytes from neural tissue transplanted into newborn mouse brain. Neurosci Lett 37:307-312.

Jacque C, Suard I, Collins P, Raoul M (1986) Identification of astrocytcs after intracercbral transplantation. Dev Neurosci 8:142-149.

Jacque C, Suard I, Ignacio V, Collins P, Raoul M, Baumann N (1988) Time-course expression of GFAP by implanted astrocytes after intracranial grafting of immature and mature brain tissues. Prog Brain Res 78:387-393.

Jacque C, Suard I, Collins PV, Baumann N (1991) Migration patterns of donor astrocytes after reciprocal striatum-cerebellum transplantation into newborn hosts. J Neurosci Res 29:421-428.

Lachapelle F, Gumpel M, Jacque C, Duc P, Baumann N (1984) Transplantation of CNS fragments into the brain of Shiverer mutant mice: extensive myelination by implanted oligodendrocytes. I. Immunohistochemical studies. Dev Neurosci 6:325-334.

Lachapelle F, Lapie P, Gansmüller A, Villarroya H, Gumpel M (1990) Patchy myelination pattern in the jimpy mouse brain: immunohistochemical study. Glia 3:375-384.

Lindsay R, Raisman G (1984) An autoradiographic study of neural development, vascularization and glial cell migration from hippo- 
campal transplants labelled in intermediate explant culture. Neuroscience 12:513-530.

Reynolds R, Wilkin P (1988) Development of macroglial cells in rat cerebellum. II. An in situ immunohistochemical study of oligodendroglial lineage from precursor to mature myelinating cell. Development 102:409-425.

Small R, Riddle P, Noble M (1987) Evidence for migration of oligodendrocyte-type 2 astrocyte progenitor cells into the developing rat optic nerve. Nature 328:155-157.
Suard I, Collins P, Ignacio V, Jacque C (1989) Implantation of rabbit embryo brain fragments into newborn mice: integration and survival of xenogeneic astrocytes. J Neurosci Res 23:172-179.

Zheng J, Ivarson B, Collins P (1986) Monoclonal antibodies to GFAP epitopes available in formaldehyde fixed tissue. Acta Pathol Microbiol Scand [A] 94:353-361.

Zhou HF, Lee LHC, Lund R (1990) Timing and patterns of astrocyte migration from xenogenic transplants of the cortex and corpus callosum. J Comp Neurol 292:320-330. 